\title{
Ophthalmic Examinations Supplemental Qualifiers Dataset
}

National Cancer Institute

\section{Source}

National Cancer Institute. Ophthalmic Examinations Supplemental Qualifiers Dataset. NCI

Thesaurus. Code C147229.

A dataset containing supplemental information, specifically non-standard variables, to parent records in the ophthalmic examinations domain. 